ISSN: 2162-3104 Print/ ISSN: 2166-3750 Online Volume 7, Number 2, March/April (2017) pp. I-III (C) Journal of International Students http://jistudents.org/

\title{
Resilience for a World in Flux
}

\author{
Chris R. Glass
}

Old Dominion University, USA

There is no question that global student mobility faces significant headwinds in the current geopolitical context. The rise of nationalism worldwide has led many international researchers to reflect on their role as educators and leaders. Resilience is vital during such tumultuous times. The popular definition of resilience is the capacity to quickly recover from difficulties and setbacks. The term is often misunderstood for a type of sturdy individualism that some people possess more than others or the immunity from stress and negative emotions. There is another, more empirically-based, understanding of resilience. Diane Coutu (2002) outlines three dimensions of resilience: (a) a staunch acceptance of reality; (b) deep belief buttressed by strongly held values; and (c) an uncanny ability to improvise. Coutu (2002) emphasizes: "You can bounce back from hardship with just one or two of these qualities, but you will only be truly resilient with all three" (p. 4). I believe, as international researchers and educators, we must be resilient in a world where the policies and politics around international students are increasingly in flux.

In my view, a staunch acceptance of reality means fully embracing co-existing realities of international education and exchange. On the one hand, as illustrated in this issue of the journal, researchers are interested in empirical evidence of local students becoming more global - developing intercultural competence, pursuing global careers, or seeing themselves as citizens in a global society. Similarly, there is an interest in ways to measure the extent to which international students become more local - building local networks and friendships, engaging the local community, and applying knowledge to local contexts. At the same time, we, as researchers and practitioners, must also embrace a co-existing reality: we must recognize that patterns of global student mobility reflect persistent inequities and imbalances. Educational exchange often leads to brain drain driven by competition among the most developed nations for top scientific and 
academic talent. Likewise, the experiences of international students at host institutions is often tainted by a sense of isolation, discrimination, and sometimes threats to their safety. A staunch acceptance of reality means examining all aspects of internationalization as part of our research efforts.

A staunch acceptance of reality must be buttressed by strongly held values. To be clear, I do not mean that researchers should report findings that are only consistent with their preexisting beliefs or offer personal commentary when hard empirical work is demanded. Rather, research that is buttressed by strongly held values uses empirical approaches to interrogate the gap between those values and reality - values such as promoting global engagement and understanding, engaging in civic responsibility beyond local contexts, fostering the appreciation for languages and cultures, and strengthening foreign relations and peace building among nations. Researchers must not only conduct rigorous research studies to determine gaps between the espoused values of nations and institutions and the experiences of international students; we must also understand the national and institutional conditions under which these core values are experienced by all students, regardless of ethnicity or socioeconomic status. One of the hallmarks of my own research has been a focus on students' sense of belonging. Whereas traditional international student adjustment research has focused on "barriers" and "challenges" to adjustment, my research reflects the value of resilience-oriented approaches to adjustment, which emphasize the importance of promotive factors (e.g., co-curricular involvement, inclusive curricula, etc.) and protective factors (e.g. belonging). My research explores the conditions under which acculturative stress produces growth, learning, and development. Several articles in this issue highlight such conditions under which international students thrive and foster cross-cultural interaction among national, co-national, and host national students that achieve full educational benefits of internationalization.

Finally, along with a staunch acceptance of reality and strongly held values, researchers must also develop an uncanny ability to improvise in a world in flux. Today, over 1 million international students study at U.S. colleges and universities, and there are nearly 5 million globally mobile students worldwide. The rise in study mobility has coincided with rising nationalism whose extent and impact is not fully clear. What is clear is that our work as researchers is more important than ever. Belonging, as I have emphasized in my research, is not merely a sense of social connectedness; it also involves participation in the leadership of the institution. A recent report by the Association of Governing Boards (2016) stated:

Diversity without inclusion is only a metric. Inclusion recognizes and embraces the need for all members of the institutional community to have a sense of ownership in the 
institution and a place of belonging. It requires sustained and intentional institutional commitment and action. Tolerance is passive and may be a starting point. Inclusion is active and reflects the continuing character of a campus. (p. 6)

International students need a voice. Researchers and practitioners must improvise ways to ensure that international students' voice is heard - on their campuses and in the research literature. A resilience perspective asks how to support people and create organizations that know how to recover, persist, and even to thrive in the face of change. As national politics fluctuates, we must understand the structures and forces within our institutions that buttress international students' resilience.

This issue of the journal poses these important questions; it does so from many points of view. It explores Brazilian and Nigerian international students' conceptions of learning; Chinese students during cross-cultural transitions and motivations for studying in the U.S. In this issue, researchers explore important issues of mental health and well-being, examining anxiety among international students, as well as the role of attachment, travel experiences, and English proficiency in international students' acculturative stress and depressive symptoms. This issue also sheds light on emerging contexts in our interconnected world, including the "digital experiences" of international students. It depends our understanding of complex dimensions of students' identities and experiences, including "the presentation of self" and multi-lingual international students. It reviews an important new book, International Higher Education's Scholar-Practitioners, on the intersection of research in practice so our work has maximum impact. The work of the journal continues to be of vital importance to a world in flux.

\section{REFERENCES}

Association of Governing Boards (2016). Governing board accountability for campus climate, inclusion, and civility. Washington, D.C.: Author.

Coutu, D. L. (2002). How resilience works. Harvard Business Review, 80(5), 1-8.

CHRIS R. GLASS, PhD, is Assistant Professor and Graduate Program Director (Higher Education and Community College Leadership) at Old Dominion University. His research and writing focuses on international students, MOOCs, and publicly engaged scholarship. Dr. Glass is also the author (with Wongtritrat and Buus) of International Student Engagement: Strategies for Creating Inclusive, Connected, and Purposeful Campus Environments (Stylus, 2014). 